\title{
O Tanztheater e suas imagens
}

\author{
Rafael Henrique Viana Sertori \\ Doutorando no PGEHA dA USP
}

Esse artigo se apresenta como uma tentativa de realizar um exercício de reflexão - por um lado arriscado, mas, por outro, talvez válido - em torno da discussão muito presente na pós-modernidade sobre a "imagem". Arriscado, pois não pretendo abordar as linguagens que geralmente ocupam o centro dessa reflexão estética na contemporaneidade, tais como o cinema, a fotografia, as artes visuais, as mídias digitais e a chamada "tela total". Indo por outro caminho, escolho a linguagem da dança para pensar se é possível identificarmos, em seus modos específicos de operar a criação e a fruição artística, a presença de imagens que nos lançam em zonas de indeterminação, de desconforto, de mistério: de enigma. Arriscado, ainda, pois:

Frequentemente, nos encontramos diante de um imenso e rizomático arquivo de imagens heterogêneas difícil de dominar, de organizar e de entender, precisamente porque seu labirinto é feito de intervalos e lacunas tanto como de coisas observáveis. Tentar fazer uma arqueologia sempre é arriscar-se a pôr, uns junto a outros, traços de coisas sobreviventes, necessariamente heterogêneas e anacrônicas, posto que vêm de lugares separados e de tempos desunidos por lacunas. Esse risco tem por nome imaginação e montagem. ${ }^{\mathrm{I}}$

${ }^{\text {I }}$ DIDI-HUBERMAN, Georges. "Quando as imagens tocam o real”. Tradução de Patrícia Carmello e Vera Casa Nova. In: Pós, Belo Horizonte, v. 2, n. 4, p. 204-219, nov. 20I2, p. 2 II. 
Desse modo, tentarei mais implicar um pensamento reflexivo partindo da linguagem da dança e menos aplicar os conceitos elaborados em torno da discussão sobre a imagem, uma vez que "se aquilo de que somos passíveis foi antes tecido por conceitos, como poderia nos atingir? Como poderia nos comover se já sabemos de que, através de quê, com o quê e para quê é feito?”. 'Logo, a principal referência que estrutura o debate aqui proposto é o artigo "Imagem e enigma", ${ }^{3}$ de Ricardo Fabbrini. Longe de querer atualizar ou fazer uma revisão das ideias contidas em tal material, inspiro-me no referido artigo para refletir acerca das seguintes questóes: seriam as artes cênicas (para além do recurso de inserirem projeçóes videográficas em diversos espetáculos na contemporaneidade), produtoras de imagens? Em caso afirmativo, como podemos operar tal reflexão estética? Enquanto arte da presença, podemos encontrar imagens-enigmas na dança, tendo em vista sua difícil apreensão pela lógica da significação ou dos imperativos de comunicação? Poderíamos dizer que a produção de imagens de resistência na dança parte da própria instauração de uma outra gramática dos corpos proposta por essa linguagem (a qual pode ser lida como expressão da crítica a um corpo codificado e normatizado pelos modos de vida em sociedade)? Em suma: como podemos operar a reflexão estética sobre a imagem nas artes da presença, para além do fato de elas incorporarem (ou não) outras mídias digitais e tecnológicas em seu fazer? Para tentar avançar com tais indagaçôes, abordarei a Dança Moderna ${ }^{4}$ alemã (de modo geral), e o Tanztheater's de Pina Bausch (de

${ }^{2}$ LYOTARD, Jean-F. "Algo assim como: comunicação... sem comunicação.” In: PARENTE, André (Org.). Imagem-máquina: a era das tecnologias do virtual. São Paulo, Editora 34, 1993, p. 260.

${ }^{3}$ FABBRINI, Ricardo. "Imagem e enigma”. In: Revista Viso: Cadernos de estética aplicada - Programa de Pós-Graduação em Filosofia da UFF, v. Io, n. I9, jul-dez/2or6.

${ }^{4}$ Movimento de dança que tem suas origens no final do século XIX, início do século XX; dentre os seus objetivos, estava a busca pela libertação das regras rígidas impostas pelo balé clássico. Seus principais precursores foram: Isadora Duncan, Doris Humphrey, Ted Shaw, Ruth St. Denis, Loie Fuller, Martha Graham (nos EUA); e Emile-Jacques Dalcroze, Mary Wigman, Rudolf von Laban e Kurt Jooss (na Alemanha).

${ }^{5}$ No meio acadêmico, acredita-se que quem primeiro empregou a expressão Tanztheater tenha sido o bailarino, coreógrafo e pedagogo alemão Kurt Jooss, em seu texto $A$ linguagem do Tanztheater, de 1935. Dança teatral é o termo sugerido pela Profa. Dra. Sayonara Pereira (ECA/USP), como o que melhor traduz a expressão Tanztheater. No entanto, em seu livro Ras- 
modo específico), enquanto campo de análise e reflexão, tentando evidenciar como tais propostas artísticas podem ser percebidas como poéticas de resistência, produzindo "imagens sobreviventes".

Desse modo, escolhi a linguagem da dança para elaborar essa escrita basicamente por três motivos: o primeiro se justifica pelo fato de essa linguagem estar diretamente vinculada ao tema das alteraçôes na experiência estética ao longo dos tempos (uma experiência que não acontece senão pela via do corpo). Portanto, poderíamos dizer que, no caso da dança, pensar sobre a produção de imagens é, necessariamente, indagar-se acerca de como se dão (e, também, de como se deram) as estruturações dos corpos que produzem essas imagens. Didi-Huberman revela que "cada vez que depomos nosso olhar sobre uma imagem, deveríamos pensar nas condições que impediram sua destruição, sua desaparição". ${ }^{6}$ De modo semelhante, mas em sentido oposto, pergunto se cada vez que nos deparamos com uma imagem produzida pela dança - pelos modos como a dança constrói certa imagem a partir da reelaboração da gramática dos corpos em movimento - não deveríamos nos perguntar quais foram as condições que a tornaram possível de existir? Acredito que pensar em como se dá a organização poética dos corpos que instauram tais imagens é tarefa crucial para entendermos se as imagens criadas pela dança serão imagens-enigmas ou se serão "mais do mesmo". Contudo, isso deve ser levado em consideração sem perdermos de vista o que aponta Fredric Jameson:

Não se trata de uma recuperação do corpo de um modo ativo e independente, mas de sua transformação num campo passivo e móvel de "registro" através do qual porções tangíveis do mundo são consideradas e então ignoradas na inconsistência permanente de um aparelho sensorial hipnotizado. ${ }^{7}$

O segundo motivo apresenta-se pelo fato de que, a meu ver, entre as chamadas "artes cênicas", a linguagem da dança é uma das que mais efetivamente tros do Tanztheater no processo criativo de ES-BOÇO (São Paulo, Annablume, 2oıo), ela defende o uso da expressão Tanztheater, sem a necessidade de se fazer traduções.

${ }^{6}$ DIDI-HUBERMAN, Georges, op. cit., p. 2Io.

7 JAMESON, Fredric. "Transformações da imagem na pós-modernidade.” In: A cultura do dinheiro: ensaios sobre a globalização. Petrópolis, RJ, Vozes, 200I, p. II6. 
opera a força não comunicativa das artes, produzindo um "efeito de assombro na espera, uma abertura fundamental para além de sua submissão ao paradigma comunicacional", ${ }_{8}^{8}$ atuando para evitar a "dissolução da arte na comunicação, hoje pacificamente aceita". ${ }^{9}$ Ou seja, enquanto arte da presença, a dança "reagiria, assim, ao baralhamento, senão indistinção, entre arte e comunicação", ${ }^{\text {Io }}$ provocando zonas de indiscernibilidade na fruição a partir da experiência estética com essa linguagem, de onde "resultaria a distância, o mistério, o enigma" das imagens produzidas pela dança. Teríamos, portanto, uma comunicabilidade circulando pela linguagem da dança que "escapa à atividade comunicacional, a qual não é uma receptividade, mas algo que se maneja, que se faz" ${ }^{12}$ Dito de outra maneira:

Sendo as propriedades qualitativas (ou dados sensíveis de uma obra de arte) da ordem do improvável, qualquer tentativa de convertêlas em unidades de informação estaria malograda, porque sempre remanesceria algo do sensivel que escapa ao enquadramento (Gestell) pelas tecnologias da comunicação. ${ }^{\mathrm{I3}}$

Já o terceiro e último motivo se dá pelo fato de podermos dizer que a dança, pela sua difícil apreensão a partir dos sistemas hegemônicos de representação e comunicação, devolve "à fruição o imprevisto - ou seja, o que de súbito irrompe em meio ao ramerrão simultaneamente festivo e lutuoso do dia a dia", ${ }^{14}$ forçando o pensamento e o esquematismo da imaginação, garantindo à experiência estética a sua força emancipatória: algo que nos pode conduzir à experiência de liberdade. Segundo Vladimir Safatle, a

${ }^{8}$ FABBRINI, Ricardo. "Estética e crítica da arte em Jean-François Lyotard”. In: O que nos faz pensar, Rio de Janeiro, v. 26, n. 40, jan.-jun., 2017, p. 47-77; p. 74.

9 Id., "Imagem e enigma". In: Revista Viso: Cadernos de estética aplicada - Programa de Pós-Graduação em Filosofia da UFF, v. Io, n. 19, jul.-dez., 2016, p. 252.

${ }^{10}$ Id., 2017, p. 65.

II Id., 2016, p. 250.

${ }^{12}$ LYOTARD, Jean-F., op. cit., p. 259.

${ }^{13}$ FABBRINI, Ricardo, 2017, p. 70.

${ }^{14}$ Id., 20I6, p. 254. 
arte é uma questão de emancipação e a crítica cultural deve ter isso sempre em mente. Como a experiência estética é a gênese da nossa ideia de emancipação, eu não teria nenhum medo em insistir nesse aspecto. Foi a experiência estética que gerou a nossa ideia de emancipação. ${ }^{\text {Is }}$

O mesmo autor ainda nos diz que:

A liberdade, na verdade, é uma invenção estética. Foi através de contatos com obras de arte que descobrimos o que significa ser livre. A liberdade não é uma questão, embora isso seja um elemento fundamental, ligada só à sua realização social como redistribuição, como circulação de bens e riquezas. Ela é, antes de mais nada, uma experiência estética de relação ao que desconstitui nosso nome, ao que desconstitui nossa normatividade, ao que desconstitui nossos lugares, a uma maneira de relacionar-se à heteronomia sem servidão. Tudo isso foi a arte que nos mostrou. ${ }^{16}$

Agora, para adentrarmos no campo da Dança Moderna alemã e do Tanztheater, Ronaldo Brito nos diz que

a liberdade moderna não era simplesmente a afirmação de novas possibilidades: era sobretudo uma revolta, um desejo crítico frente às coisas e valores instituídos. No limite, expressava o paradoxo de um sujeito que não reconhecia mais o mundo enquanto tal. ${ }^{17}$

Sendo a modernidade marcada por um tempo histórico pressionado pela liberdade, a visão defendida nesse artigo propóe, portanto, que encaremos a Dança

is SAFATLE, Vladimir. Apud LYRA, Frederico. "Entrevista com Vladimir Safatle". In: Crise e critica: Revista latinoamericana de filosofia e politica, v. 2, n. 2, nov., 2018, pp. 184-207; 202.

${ }^{16}$ Ibid., p. 201.

${ }^{17}$ BRITO, Ronaldo. "O moderno e o contemporâneo (o novo e o outro novo)". In: Arte brasileira contemporânea: Caderno de textos $I$. Rio de Janeiro, Funarte, 1998, p. 202. 
Moderna alemã como uma arte revolucionária, que visava à emancipação e à construção de um corpo político capaz de produzir vínculo, aproximar os sujeitos e levar a sociedade a instaurar aquilo que ela ainda não consegue vislumbrar adotando, com isso, a existência das relações de tensão entre estética e política. O que é diferente de considerá-la apenas como uma manifestação artística ocupada em enfatizar e estetizar problemas que nos constituem, ocasionados pelos processos de reprodução material da vida.

Indo em direção à redescoberta do corpo e à criação de suas próprias técnicas, regras e normas, a Dança Moderna alemã buscou incessantemente sua autonomia, resgatando a força expressiva da linguagem da dança (em contraponto à mimetização de temas sentimentais e fábulas até então representadas pelo balé clássico - linguagem hegemônica da dança até os fins do século XIX). Ela estruturou-se contra uma certa configuração reificante e uniformizante da vida social, do corpo e dos processos de subjetivação, produzindo, dessa maneira, a consciência de um tempo em ruptura, evidenciando "a emergência de processos de desconstituição semântica capazes de nos implicar na abertura de transformações estruturais da sensibilidade". ${ }^{8}$ Tal aspecto relaciona-se diretamente com a produção de imagens na dança, as quais podem deter "algum enigma, que indicie algum segredo, mistério ou recuo", ${ }^{\text {I9 }}$ lançando-nos em zonas de indeterminação, de desconforto, de angústia e revolta frente ao inominável, ao irredutível, ao não-sentido.

Dentre os principais objetivos da Dança Moderna alemã, enquanto nova prática artística e proposta estética, estavam: a valorização do aspecto expressivo do corpo em oposição à significação, à mimetização e à representação; a busca pela libertação das regras rígidas impostas pelo balé clássico; a redescoberta do próprio corpo enquanto meio e norma da dança; e a expressão de sentimentos inquietantes e angústias intransponíveis, inerentes à vida da primeira metade do século XX. Segundo um dos fundadores da Dança Moderna alemã, o bailarino, coreógrafo e pedagogo húngaro Rudolf von Laban:

${ }^{18}$ SAFATLE, Vladimir. "A mais violenta das artes: expressão não-intencional e emancipação política a partir do romantismo musical". In: Artefilosofia - Revista do Programa de PósGraduação em Estética e Filosofia da Arte da UFOP, Ouro Preto, n. 24, jul., 2018a, p. 30.

${ }^{19}$ FABBRINI, Ricardo, 2016, p. 248. 
(...) o pensar por movimentos poderia ser considerado como um conjunto de impressóes de acontecimentos na mente de uma pessoa; conjunto para o qual falta uma nomenclatura adequada. Este tipo de pensamento não se presta à orientação no mundo exterior, como o faz o pensamento através das palavras; mas, antes, aperfeiçoa a orientação do homem em seu mundo interior, onde continuamente os impulsos surgem e buscam uma válvula de escape no fazer, no representar e no dançar. ${ }^{20}$

Para Laban, o bailarino era visto como aquele que traduzia, pela realização rítmica e dinâmica dos movimentos dançados, seus próprios "impulsos e ritmos fisiológicos, emocionais e intelectuais; era criador, meio e norma da própria dança, expressão não mediada da harmonia de sua vida e instrumento de acorde sintônico com a harmonia da vida universal". ${ }^{21}$ Segundo Paul Bourcier, Laban acreditava que "a dança é transcendência do homem; é o meio de dizer o indizível, da mesma forma que a característica da poesia é ultrapassar o sentido estrito das palavras". ${ }^{22}$ Nesse contexto, a dança passou a ser encarada como "experiência do cosmos em forma de movimento" ${ }^{23}$ e, enquanto linguagem artística, foi cada vez mais se distanciando dos padrôes miméticos, dos limites cognitivos da representação e dos códigos comunicacionais que insistiam em aprisionar o corpo em uma determinada gramática de movimentos e significações preestabelecidas, impedindo-o de explorar outros modos de sua manifestação expressiva. Assim, a experiência da Dança Moderna alemã poderia ser lida a partir do regime de emancipação que a arte é capaz de fazer circular - "a emancipação do sujeito diante de sua condição de indivíduo" -, ${ }^{24}$ sendo "que é a realização da arte como linguagem expressiva que permite aos sujeitos fazerem a experiência da liberdade”. ${ }^{25}$ Ou seja, poderíamos

${ }^{20}$ LABAN, Rudolf. Dominio do movimento. Lisa Ullmann (Org.). São Paulo, Summus, 1978 , p. 42.

${ }^{21}$ ROPA, Eugenia. A dança e o agit-prop: os teatros não teatrais na cultura alemã do início do século XX. São Paulo, Perspectiva, 20I4, p. 78.

${ }^{22}$ BOURCIER, Paul. História da dança no ocidente. São Paulo, Martins Fontes, 1987, p. 295.

${ }^{23}$ Ibid., p. 85 .

${ }^{24}$ SAFATLE, Vladimir, op. cit., p. 3I.

${ }^{25} \mathrm{Id}$. 
inclusive dizer que a Dança Moderna também surgiu "como expressão maior de uma subjetividade capaz de deixar para trás as convenções, as estruturas de percepção ligadas ao senso comum e ao hábito", ${ }^{26}$ uma vez que existir como um corpo sempre será existir mais do que si mesmo. Para as pesquisadoras de dança Aline Haas e Angela Garcia, a Dança Moderna instaurou-se:

(...) como necessidade de ser uma arte que promovesse e provocasse a liberdade e a exploração total do corpo a partir de temas abstratos ou concretos; com o despertar do homem para sua própria natureza, diversificando novas técnicas corporais e linhas coreográficas que iam ao encontro das necessidades de expressar acontecimentos de sua época, seus próprios sentimentos e não apenas de personagens fictícios; é a dança da libertação do corpo e de seus movimentos; é a dança que retrata todas as experiências vitais da sociedade e dos seres humanos em que, mais uma vez, esses estão engajados e conscientes no mundo em que vivem. ${ }^{27}$

Como podemos observar por meio da leitura do trecho citado, a ruptura com quaisquer padrões de ilusão, representação e ficção na dança já começava a se tornar um dos principais objetivos dessa linguagem artística, assim como a abertura a temas e acontecimentos presentes na vida social e, portanto, política. A expressão estética (não egológica, nem objetificadora), ${ }^{28} \mathrm{em}$ contraponto ao paradigma comunicacional, também se tornou um propósito a ser perseguido pela "nova dança” alemã, uma vez que tal paradigma implica "exteriorização no interior de um regime de determinação submetido a princípios normativos já previamente assegurados e consensuais de interpretação de sentido, de valores, de conflitos e de definição do melhor argumento". ${ }^{29}$ Por outro lado, "ao invés de

${ }^{26}$ SAFATLE, Vladimir, Revolução politica, instauração estética. 2018b, p. 52. Disponível em: https://www.academia.edu/38037779/Curso\%20_integral_Revoluç\%C3\%25\% 20A3o_pol\%25\%20C3\%ADtica_instauraç ${ }^{2}$ ao_estética_2018_. Acesso em: 22 jan. 2020.

${ }^{27}$ HAAS, A.; GARCIA, A. Ritmo e dança. Canoas, Editora da ULBRA, 2003, p. IOI.

${ }^{28}$ SAFATLE, Vladimir, 2018a, p. 30.

${ }^{29}$ Ibid., p. 29. 
reiterar o socialmente valorizado, a expressão nega a realidade ao contrapor-lhe o que não se iguala a esta, mas não a renega". ${ }^{30}$ Nessa perspectiva, podemos considerar que a Dança Moderna alemã foi uma arte engajada em consolidar-se a partir da experiência de certa autonomia estética, reformulando por completo as bases que constituíam a criação em dança até então conhecidas e praticadas. Refundando a experiência dos sujeitos com o corpo sensível, com a dança e com a vida, uma vez que um novo modelo de conhecimento do corpo foi proposto pela Dança Moderna - ou seja, "nem objeto físico, nem corpo biológico, mas um corpo energético, feixes de forças" - ${ }^{3 \mathrm{I}}$ a expressão estética presente em tal linguagem artística alterou, de certa maneira, as estruturas da percepção, resgatando "a força de implicar afetivamente sujeitos em uma dinâmica de transformação estrutural de si e do mundo, pois a expressão é presença daquilo que não contava na imagem de si e nem nas imagens do mundo". ${ }^{32}$

Podemos mesmo dizer que a Dança Moderna alemã se instaurou enquanto linguagem expressiva integralmente implicada com a ruptura e com a libertação dos padrões sociais em curso, os quais delegavam sobre os modos de viver, criar, pensar, olhar e perceber o mundo e a vida. Nesse sentido, não seria equivocado pensarmos que, em relação à produção de imagens advindas dessas obras de dança, havia algo mais que imagens "sem recuo, sem relevo, sem perspectiva, sem enigma, sem mistério, sem avesso", ${ }^{33}$ assim como no próprio corpo já havia a intenção de se procurar por algo que surpreendesse o esquematismo da percepção reificante. Roger Garaudy afirma que a dança desse período:

(...) deixava de ser um "divertimento" para trazer o homem de volta ao seu próprio centro, onde ele se interroga sobre seus fins e seu poder. A educação podia, a partir daí, reconstruir-se sobre uma nova base; a dança transformava em movimentos controlados as reações espontâneas do homem em sua relação com a natureza, com os outros homens, com seu próprio futuro. ${ }^{34}$

${ }^{30}$ Ibid., p. 30.

${ }^{31}$ GIL, José. O movimento total: o corpo e a dança. São Paulo, Iluminuras, 2013, p. I22.

${ }^{32}$ SAFATLE, Vladimir, 2or8a, p. 30.

${ }^{33}$ FABBRINI, Ricardo, 2016, p. 245.

${ }^{34}$ GARAUDY, Roger. Dançar a vida. São Paulo, Nova Fronteira, 1990, p. 130. 
Seguindo objetivos semelhantes e dando prosseguimento ao desenvolvimento da expressão e autonomia estética presentes na linguagem da Dança Moderna alemã, na segunda metade do século XX emerge o significativo trabalho poético e artístico da coreógrafa e bailarina alemã Pina Bausch (1940-2009), diretora da companhia Tanztheater Wuppertal-Pina Bausch entre os anos de 1973 a 2009. É com o trabalho desenvolvido junto aos bailarinos da companhia Tanztheater Wuppertal-Pina Bausch que a linguagem do Tanztheater ${ }^{35}$ se expande para o mundo e, com ele, a possibilidade de se continuar a criação em dança com bases estruturadas na autonomia estética. Pina Bausch extrapolou as fronteiras que separavam as várias linguagens artísticas, misturando e recriando aspectos que, até então, eram considerados como específicos a determinadas artes, como o teatro e as artes plásticas, por exemplo. Com seu Tanztheater, ela criou sua própria linguagem expressiva e concretizou poética, estética e cenicamente o hibridismo das várias linguagens artísticas (aspecto marcante do Tanztheater alemão, conferindolhe sua própria autonomia de criação), ressignificando e alterando o que o seu tempo histórico entendia e reconhecia enquanto dança. De acordo com Laurence Louppe:

Em suma, o Tanztheater criava um teatro verbal virtual, a partir do qual o ato humano, caracterizado e impregnado por todos os seus determinismos sociais, pôde ser deslocado para um cenário que lhe permitiu a encenação pelo movimento. Tal sucedeu através de um tratamento apropriado do movimento, menos em vista de uma expressividade mimética do que de um trabalho sobre a simbólica profunda do movimento e das suas constelações relacionais - direções, tensões, acentos, ritmos, entre outras -, que converteu o Tanztheater numa arte não naturalista, numa arte que dá ao espectador informações sobre a economia energética dos atos humanos individuais ou coletivos, muito mais do que sobre a aparência formal desses atos. ${ }^{36}$

${ }^{35}$ Como principais protagonistas do Tanztheater alemão, para além do precursor Kurt Jooss (ıOI-1979) e de Pina Bausch, encontramos também as bailarinas e coreógrafas alemãs Reinhild Hoffmann (1943) e Susanne Linke (1944).

${ }^{36}$ LOUPPE, Laurence. Poética da dança contemporânea. Lisboa, Orfeu Negro, 2oI2, p. 273. 
Enquanto diretora e coreógrafa, Pina Bausch trabalhava "sobre a simbólica profunda do movimento" a partir de temas referentes ao cotidiano do ser humano e de suas vidas psíquica, social e política, levando para a cena, muitas vezes, o que acontece nas entrelinhas das relaçôes intersubjetivas. Segundo Fabio Cypriano, Pina Bausch faz "uso do subjetivo como estratégia para aflorar o social. Ela procura revelar, assim como Foucault, que as estruturas de poder estão localizadas nos indivíduos". ${ }^{37}$ A partir de sua linguagem poética própria, Pina Bausch conseguiu criar um corpo que buscava expressar aquilo que não é possível nominar; aquilo que causa inquietude, perplexidade, dor, revolta e interrogação; aquilo que não encontra uma gramática de fácil acesso, significação e apreensão, realizando, dessa maneira, "uma efetuação que tenta criar honestamente uma experiência estética”.$^{38}$ Como ela mesma diz: "é a vida, o que sucede à nossa volta que inevitavelmente constitui uma influência. Não diria que sou influenciada por fatores artísticos propriamente ditos. Tento falar da vida. O que me interessa é a humanidade, as relações entre os seres humanos" ${ }^{39}$

Por conseguinte, podemos supor que seu Tanztheater constituiu-se também enquanto "expressão da crítica à linguagem reificada da vida ordinária, linguagem essa submetida aos imperativos comunicacionais e seus modos de constituição de objetos.” ${ }^{40}$ Nesse percurso, Pina Bausch propôs a criação de uma nova gramática corporal, desenvolvendo um modo singular de esculpir certa dinâmica dos corpos na dança. Sua linguagem revela a presença de um corpo expressivo a partir da reelaboração dos gestos e do que, até então, se reconhecia enquanto movimento dançado. Fabio Cypriano nos diz que:

$\mathrm{Na}$ dança-teatro de Bausch, o corpo passa por novos desafios. A exploração de limites amplia a gramática de movimento, que vai além da técnica do repertório dos bailarinos clássicos e mesmo modernos. O corpo se torna um espaço de resistência frente às diversidades e nega o caráter supra-humano em que a técnica, em geral, busca formatá-lo. Assim, corpo e sentimentos representam no palco

\footnotetext{
${ }^{37}$ CYPRIANO, Fabio. Pina Bausch. São Paulo, Cosac Naify, 2005, p. 31.

${ }^{38}$ FABBRINI, Ricardo, 2016, p. $25 \mathrm{I}$.

${ }^{99}$ CYPRIANO, Fabio, op. cit., p. 24.

${ }^{40}$ SAFATLE, Vladimir, 20I8a, p. 6r.
} 
uma unidade; ambos são a expressão da fragilidade da existência humana. ${ }^{4 \mathrm{I}}$

Desse modo, a nova gramática dos corpos proposta por Pina Bausch "não é apenas um exercício de virtuose, mas a conquista da expressividade através da reversão da normatividade em princípio de desconstituição da própria forma" ${ }^{42}$ A coreógrafa aprofundava-se sem cessar no campo da expressão, revelando com sua linguagem poética o que há de mais sutil e invisível da vida humana, propondo um intenso processo de constituição e desconstituição dos sujeitos, um embaralhamento na percepção e na fruição estética. As imagens produzidas por sua dança nos lançam em zonas de experiência e conhecimento porque instauram a possibilidade de experienciarmos outros modos de percepção do corpo, da cena, da vida, garantindo uma "das grandes forças da imagem” que é "criar ao mesmo tempo sintoma (interrupção no saber) e conhecimento (interrupção no caos)". ${ }^{43}$ Ela desenvolveu a sua linguagem como veículo de uma sensibilidade outra, propondo ao espectador um "compartilhamento emocional de impulsos" e uma “autêntica experiência do espiritual”. ${ }^{44}$ Para o filósofo português José Gil: "é como se o 'método Bausch' fizesse vir à superfície camadas soterradas de emoções e de sentimentos que nenhum outro tipo de movimento conseguiu alcançar". ${ }^{45}$ O que nos leva a supor que aquilo que Pina Bausch propóe enquanto experiência estética é um "impulso de forçagem da forma para fora de si mesma”. ${ }^{46}$

As obras de Pina Bausch não narram histórias, mas evidenciam partes do processo criativo a partir de células coreográficas e da reconfiguração expressiva dos corpos, do movimento, da palavra, dos sons, ruídos, imagens, objetos, figurinos, adereços e até mesmo da reordenação do espaço, o qual vai se construindo e se transformando de acordo com cada cena apresentada. Em sua poética, é possível notarmos um entrelaçamento entre real e imaginário, público e privado, biográfico e ficcional. A ação dramática dá lugar a situações dinâmicas sem seguir

\footnotetext{
${ }^{41}$ CYPRIANO, Fabio, op. cit., p. 29.

${ }^{42}$ SAFATLE, Vladimir, 2018a, p. 57.

${ }^{43}$ DIDI-HUBERMAN, op. cit., p. $2 \mathrm{I} 4$.

${ }^{44}$ LEHMANN, Hans-Thies. Teatro pós-dramático. São Paulo, Cosac Naify, 2007, p. 36I.

${ }^{45}$ GIL, José, op. cit., p. 163.

${ }^{46}$ SAFATLE, Vladimir, op. cit., p. 59.
} 
uma linha narrativa contínua; a percepção dos espetáculos se constitui enquanto perspectivas múltiplas e simultâneas, de modo que a fragmentação presente nas obras nos faz entrever o próprio caos. A encenação, tal como é construída pela coreógrafa, nos revela que "por trás da identidade fixada há uma subjetividade dinâmica a ser despertada e usada para fins transformadores (tanto na identidade do indivíduo, quanto da sociedade)". ${ }^{47}$ Portanto, de um modo geral, poderíamos dizer que sua dança é constituída pelos movimentos que se materializam em um determinado corpo-espaço, seguindo uma outra lógica do tempo que não a do tempo cronológico e linear, bem como pelos gestos-ação dos corpos físico, biológico, sensível, subjetivo e psíquico, os quais buscam ininterruptamente por uma redefinição, produzindo, assim, imagens na cena.

Para Hans-Thies Lehmann, a dança "não formula sentido, mas articula energia; não representa uma ilustração, mas uma ação". ${ }^{48}$ Ou seja, o corpo que a dança apresenta será quase sempre uma constante matéria-em-processo, o qual não cessa de se reapropriar e se reinventar no jogo entre interno e externo, visível e invisível, matéria e espírito, passado e futuro. E é justamente essa noção de corpo que nos é apresentada pelos diversos processos de materialização e configuração do pensamento em dança; processos esses que buscam criar e manifestar em estética (em imagens em movimento), aquilo que ainda não existe no mundo visível ou o que não é possível nominar; processos implicados em tecer fios coreográficos a partir do invisível e que tentam dar forma a uma experiência que só se constitui no (e através do) próprio corpo em movimento. Laurence Louppe nos diz que "na maior parte do tempo, diferentes corpos circulam, visíveis ou invisíveis, no interior dos corpos dançantes, como vagas misteriosas, cujas referências corporais se confundem ou se sobrepóem". ${ }^{49}$ A mesma autora nos diz, ainda, que:

(...) a dança empenha-se no advento de um corpo que não é dado previamente. Por outras palavras, a dança explora uma multiplicidade de corpos, cada um contendo como que uma partitura secreta, um

47 BAUMGÄRTEL, Stephan. "Subjetividades na cena contemporânea: expor a encenação citacional e suas lacunas”. In: Revista FIT - Festival Internacional de Teatro, São José do Rio Preto (SP), 2009, p. I29-I33; p. I3I.

${ }^{48}$ LEHMANN, Hans-Thies., op. cit., p. 339.

${ }^{49}$ LOUPPE, Laurence, op. cit., p. 8I. 
imenso leque de possibilidades e de tonalidades poéticas, algo que Laban designa por assinatura corporal. Estes corpos transmutam-se através das épocas, das culturas e dos indivíduos e, segundo mecanismos individuais, entre situações e respostas. Não são somente um campo de interferências, mas um campo suscetível de organizar tais interferências. Dançar consistiria, assim, em tornar legível a rede sensorial que o movimento explora e cria a cada instante..$^{50}$

Em síntese, podemos dizer que a rede sensorial que a dança torna legível se dá na medida em que, por meio e através do movimento, o corpo encarna, circunscreve e evoca as experiências que temos com aquilo que é desconhecido, que nos causa inquietude, desconforto e que nos lança em zonas de indeterminação; com aquilo que é da ordem do inconsciente, do indizível, do não-dito, produzindo outras e novas corporeidades, as quais poderão resultar em novas manifestações estéticas e ações políticas, por exemplo. Ou seja, o corpo da dança é capaz de desestabilizar as noçóes já conhecidas de corpo, libertando-o de sua mera finalidade e organização de corpo físico e biológico. A esse respeito, José Gil nos diz que

trata-se de libertar o corpo entregando-o a si próprio: não ao corpomecânico nem ao corpo-biológico, mas ao corpo penetrado de consciência; ou seja, ao inconsciente do corpo tornado consciência do corpo (e não consciência de si ou consciência reflexiva de um "eu")..$^{\text {sI }}$

Por esse motivo, podemos mesmo dizer que a experiência estética com a linguagem da dança, em suas relaçóes com a comunicabilidade, "faz vibrar o que em nós pode emergir para além da capacidade de representação de um Eu". ${ }^{2}$ A expressão estética em tal linguagem vai além da expressão egológica ou objetificadora. De modo semelhante, a construção de novas gramáticas corporais se realiza como emergência de um corpo expressivo enquanto fluxo de despersonalização, em

\footnotetext{
${ }^{50}$ Ibid., p. 85 .

${ }^{5 I}$ GIL, José, op. cit., p. 22.

$5^{2}$ SAFATLE, Vladimir, 2or8a, p. 29.
} 
direção à heteronomia, haja visto que o corpo da dança "entra em uma espécie singular de vida, estranhamente instável e, ao mesmo tempo, estranhamente regrada; estranhamente espontânea, estranhamente inteligente e certamente planejada". ${ }^{33}$

Para finalizar, considerando que as imagens que a dança pode criar não são imagens estáticas (a não ser pelas fotografias que são produzidas dos espetáculos), a análise que se propõe a refletir sobre o caráter imagético presente na linguagem da dança não deve nunca deixar de lado a experiência construída pelo próprio espectador, fruidor, receptor de uma obra cênica, uma vez que é ele quem vai captar, entre um movimento e outro, as imagens presentes na dança, instauradas pelos corpos dançantes em diálogo com o espaço cênico. No entanto, no atual estágio cultural em que estamos, no qual "o espaço social está completamente saturado com a cultura da imagem", 54 devemos buscar por novos modos de nos colocar frente às obras de arte; ou seja, buscar pela "percepção marcada pela demora, pelas hesitaçôes, pela perda de tempo e pelo tempo perdido, pela paciência em desvelar o segredo de uma imagem, uma face nela que apenas se deixa entrever". ${ }^{5}$ Logo, "uma imagem bem olhada seria, portanto, uma imagem que soube desconcertar, depois renovar nossa linguagem, e portanto nosso pensamento". ${ }^{56}$ Nesse sentido, o psicanalista, professor e pesquisador João Frayze-Pereira ${ }^{57}$ apresenta, por exemplo, a perspectiva da psicanálise implicada. Para ele, ao se relacionar com uma obra de arte, com um objeto ou manifestação artística, os sujeitos deveriam deixar-se atravessar pela experiência, sem necessariamente procurar nelas o que já se conhece, objetivando terem suas buscas por significação e sentido instantaneamente satisfeitas.

De forma sucinta, a psicanálise implicada propóe que pensemos diferentemente o que já se sabe, em vez de legitimarmos o já conhecido. Requer observação atenta e demorada da obra para identificarmos suas singularidades; ou seja, a psicanálise implicada é "derivada das artes ou engastada nelas, pois não é uma forma

53 VALÉRY, Paul. "Filosofia da dança”. Tradução de Charles Feitosa. In: O percevejo online, Rio de Janeiro, v. 03, n. o2, agosto-dez, 2oII, p. o9.

${ }^{54}$ JAMESON, Fredric, op. cit., p. IIs.

${ }^{55}$ FABBRINI, Ricardo, 2016, p. 253.

${ }^{56}$ DIDI-HUBERMAN, op. cit., p. 216.

${ }^{57}$ Cf.: FRAYZE-PEREIRA, J. Arte, dor: inquietudes entre estética e psicanálise. Cotia, SP: Ateliê Editorial, 2010. 
a se aplicar à matéria exterior, não é um modelo que ajusta abstratamente o objeto artístico às suas exigências teórico-conceituais" ${ }^{8}{ }^{8}$ Nessa concepção, os sentidos não buscam nos objetos da cultura os dados da realidade existente: deixa-se livre o imaginário para que possam surgir inúmeras associações, para que os objetos possam expressar sua "vida interior". Ou seja, nessa experiência da percepção, devemos buscar nossa "extraordinária faculdade de fundir-se nas coisas", significando isso um

estar no lugar, indubitavelmente. Ver sabendo-se olhado, concernido, implicado. E, contudo, mais: parar, manter-se, habitar durante um tempo nesse olhar, nessa implicação. Fazer durar esta experiência. E logo, fazer dessa experiência uma forma, depreender uma forma visual. 59

Somente encarando a experiência estética com a dança dessa maneira é que, provavelmente, poderemos entrever nela a presença de imagens-enigmas; imagens que evidenciem "acidentes no continuum da vida pós-contemporânea, quebras e lacunas no sistema de percepção do capitalismo tardio". ${ }^{60}$

\footnotetext{
$5^{8}$ FRAYZE-PEREIRA, op. cit., p. 37.

59 DIDI-HUBERMAN, op. cit., p. 215.

${ }^{60}$ JAMESON, op. cit., p. II6.
} 


\section{Referências bibliográficas}

BAUMGÄRTEL, Stephan. "Subjetividades na cena contemporânea: expor a encenação citacional e suas lacunas". In: Revista FIT - Festival Internacional de Teatro, São José do Rio Preto (SP), 2009, p. I29-133.

BOURCIER, P. História da dança no ocidente. São Paulo: Martins Fontes, 1987. BRITO, Ronaldo. "O moderno e o contemporâneo (o novo e o outro novo)". In: Arte brasileira contemporânea: Caderno de textos I. Rio de Janeiro, Funarte, 1998

CYPRIANO, Fabio. Pina Bausch. São Paulo: Cosac Naify, 2005.

DIDI-HUBERMAN, Georges. "Quando as imagens tocam o real”. Tradução de Patrícia Carmello e Vera Casa Nova. In: Pós, Belo Horizonte, v. 2, n. 4, p. 204-219, nov., 2012.

FABBRINI, Ricardo. "Imagem e enigma”. In: Revista Viso: Cadernos de estética aplicada - Programa de Pós-Graduação em Filosofia da UFF, v. Io, n. I9, jul.dez., 2016.

. "Estética e crítica da arte em Jean-François Lyotard". In: O que nos faz pensar, Rio de Janeiro, v. 26, n. 40, p. 47-77, jan.-jun., 2017.

FRAYZE-PEREIRA, João. Arte, dor: inquietudes entre estética e psicanálise. Cotia, SP: Ateliê Editorial, 20 Io.

GARAUDY, Roger. Dançar a vida. São Paulo: Nova Fronteira, 1990.

GIL, José. O movimento total: o corpo e a dança. São Paulo: Iluminuras, 2013.

HAAS, Aline Nogueira; GARCIA, Angela. Ritmo e dança. Canoas: Editora da ULBRA, 2003.

JAMESON, Fredric. “Transformaçôes da imagem na pós-modernidade.” In: A cultura do dinheiro: ensaios sobre a globalização. Tradução de Maria Elisa Cevasco e Marcos César de Paula Soares. Petrópolis: Vozes, 200I.

LABAN, Rudolf. Dominio do movimento. Lisa Ullmann (Org.) São Paulo: Summus Editorial, 1978.

LEHMANN, Hans-Thies. Teatro pós-dramático. São Paulo: Cosac Naify, 2007. LOUPPE, Laurence. Poética da dança contemporânea. Lisboa: Orfeu Negro, 2012. 
LYOTARD, Jean-F. “Algo assim como: comunicação... sem comunicação". In: PARENTE, André (Org.). Imagem-máquina: a era das tecnologias do virtual. São Paulo: Editora 34, 1993.

LYRA, Frederico. "Entrevista com Vladimir Safatle". In: Crise e crítica: Revista latinoamericana de filosofia e politica, v. 2, n. 2, nov., 2018, pp. 184-207; 202, ISSN (versão impressa): 23II-8I72.

ROPA, Eugenia. C. A dança e o agit-prop: os teatros não teatrais na cultura alemã do início do século XX. São Paulo: Perspectiva, 2014.

SAFATLE, Vladimir. "A mais violenta das artes: expressão não-intencional e emancipação política a partir do romantismo musical”. In: Artefilosofia - Revista do Programa de Pós-Graduação em Estética e Filosofia da Arte da UFOP, Ouro Preto, n. 24, julho/2or8a.

. Revolução politica, instauração estética. 20I8b. Disponível em: https: // www.academia.edu/38037779/Curso\%20_integral_Revoluç\%C3\%25\% 20A3o_po $1 \% 25 \% 20 \mathrm{C} 3 \%$ ADtica_instauraç ao_estética_2018_. Acesso em: 22 jan. 2020.

VALÉRY, Paul. "Filosofia da dança". Tradução de Charles Feitosa. In: Opercevejo online, Rio de Janeiro, v. 03, n. o2, ago.-dez, 2 oII.

Resumo: A escrita desse artigo tem por objetivo discutir a produção de imagens a partir da linguagem $\mathrm{da}$ dança, tomando como objeto de análise geral a Dança Moderna alemã e, em específico, a obra da bailarina e coreógrafa alemã Pina Bausch (19402009), à frente da companhia Tanztheater Wuppertal-Pina Bausch. As observaçôes aqui descritas caminham na direção de tentar evidenciar em que medida a experiência estética em dança pode contribuir com o campo compre-
Abstract: This article aims discussing the image production derived from the dance expression, having as overall analyses subject the German Modern Dance, specifically the work of the German dancer and choreographer Pina Baush (1940-2009), heading the Tanztheater Wuppertal-Pina Bausch Company. The observations here described attempt to show how far can the dance aesthetic experience contribute to the aesthetic thinking field about contemporary images. 
endido pela reflexão estética acerca das imagens na contemporaneidade. Palavras-Chave: imagem-enig- Modern Dance.
KeYwords: puzzle-picture; aesthetic experience; Tanztheater; German

ma; experiência estética; Tanztheater;

Dança Moderna alemã. 